\title{
GOOD INFORMATION PROCESSING: WHAT IT IS AND HOW EDUCATION CAN PROMOTE IT
}

\author{
MICHAEL PRESSLEY,${ }^{*}$ JOHN G. BORKOWSKI $\dagger$ and \\ WOLFGANG SCHNEIDER $\ddagger$ \\ *University of Maryland \\ †University of Notre Dame \\ $\ddagger$ Max-Planck-Institute for Psychological Research, Munich, F.R.G.
}

\begin{abstract}
The nature of good information processing is outlined as determined by intact neurology, information stored in long-term memory, and general cognitive tendencies, attitudes, and styles. Educators can promote the development of good information processing by promoting what is in long-term memory. This can be accomplished by teaching important literary, scientific, and cultural knowledge; teaching strategies; motivating the acquisition and use of important conceptual knowledge and strategies; and encouraging the general tendencies supporting good information processing. Good information processing can be produced by years of appropriate educational input. Good information processors cannot be produced by short-term interventions.
\end{abstract}

\section{Introduction}

For the past five years, we have advocated a strategy-oriented perspective on the nature of competent intellectual performance. The Good Strategy User model was constructed to describe and explain efficient, self-regulated thinking (e.g., Pressley, 1986; Pressley, Borkowski, \& Schneider, 1987). We viewed capable cognition in terms of interactions between neurological, cognitive, metacognitive, motivational, and general knowledge factors. In this chapter, a revision of our position is proposed, one accounting for capable information processing more adequately. The new approach is dubbed the 'good information processor' model. Before discussing it, however, the original good strategy user perspective is overviewed, since the new approach builds upon components of the old model.

\section{The Good Strategy User Model}

Good strategy users are reflective. They deploy attention appropriately as part of 
attempting academic tasks. They shield themselves from interfering distractions. In short, good strategy users have cognitive styles that support efficient thinking rather than undermining it, setting the stage for effective operation of other components of good strategy use.

Good strategy users employ efficient procedures (i.e., strategies) to accomplish complex, novel tasks. Good strategy users have repertoires of memory, comprehension, composition, and problem-solving skills. They possess essential metacognitive knowledge for implementing strategies, including knowing when and where each strategy may be useful, as well as costs associated with the strategy, such as the amount of cognitive effort it requires. Good strategy users are motivated to be strategic, believing performance can be improved by applying procedures well matched to learning challenges. They do not believe achievement is due to effort alone (i.e., simply trying hard) or to factors out of their control, such as luck, innate ability, or task difficulty.

They understand strategic actions often require deliberate effort, online monitoring, and potential revision (Borkowski, Carr, Rellinger, \& Pressley, in press). With practice, however, metacognitively-guided strategy use gives way to more consistent recognition of the need for specific strategies and the automatic execution of relevant procedures. There are many occasions, however, when strategies are not needed at all. Consistent and mature strategy use fosters development of an extensive knowledge base which often automatically mediates academic encounters. For instance, a junior high school student could use a variety of context-interpretive strategies to determine the meaning of phrases encountered in text, for example, "The handwriting was on the wall'. In contrast, another junior high student, knowing the Biblical story of Daniel and the king, might infer the meaning of the 'handwriting' phrase immediately, recalling the passage about the king"s downfall following the appearance of writing on the wall.

In short, our original model emphasized the interaction of strategic, knowledge-base, and motivational components in determining cognitive performance. Thus, 'good strategy user' was something of a misnomer, one focussing too much attention on strategies in mediating memory, comprehension, and problem-solving tasks. This chapter offers a broader framework for understanding how strategy use fits into efficient information processing.

\section{Beyond Good Strategy Use: Good Information Processing}

The good information processor model retains all major components in the good strategy user model. The additional features of good information processing highlighted in this article represents additions to the old model or new perspectives on functioning of components in the original version.

\section{New Points of Emphasis}

(1) Good information processors (henceforth referred to as GIPs) plan their thinking and behavior. GIPs are planful (Hoc, 1988; Miller, Galanter, \& Pribram, 1960). They have developed a consistent tendency to think through a course of action before they act. Their plans are often represented internally, although they can be translated into external 
representations (e.g., a flowchart detailing a problem solution). Plans guide their thinking. Thus, once an internal problem-solving flowplan is devised, GIPs proceed to follow the flow. If an impasse is reached, more planning occurs to identify ways to overcome obstacles not considered during initial planning.

Planning can be more or less deliberate, more or less conscious, more or less habitual (e.g., De Lisi, 1987), although plans are always in the service of some goal. A plan guiding a person from his home to his workplace is stored in long-term memory and activated daily without conscious effort. When the person first moved to the current residence, however, the plan was constructed and used deliberately. With routine application, it came to function automatically out of awareness except when an obstacle prevented successful execution of the routine plan (e.g., there was an auto accident blocking the roadway en route).

A complete plan often incorporates a sequence of strategies. A professor may have a plan for carrying out a research study, including strategies for obtaining funds, executing the study, analyzing the results, and preparing the writeup. A plan is not just a linear sequencing of discreet strategies, however, but rather an integration of procedures affected by particular beliefs and motivations possessed by the planner. Thus, the funding strategy interacts with execution, analysis, and report tactis. Because the professor believes funds are more available for studying cognitive planning in classrooms than in purely laboratory tasks, he or she prepares a proposal containing themes appealing to educationally-oriented granting agencies, courting them rather than basic science funding sources. Deciding to seek an education research grant affects strategies selected for getting research initiated (e.g., perhaps an observational study is designed rather than an experiment). The design strategy also constrains analytic plans and reporting strategies (e.g., whether to write only scientific articles or both scientific articles and more descriptive magazine-format papers for professional educators). Even the last strategies in the chain (i.e., writeup and reporting procedures) might have influenced the original decision to seek an educational grant. The professor may feel more comfortable with, or more interested in, reaching an educator audience.

(2) GIPs monitor their performances. They recognize that performance does not always go as well as planned and that failures can be signals to change strategies or even entire plans. Thus, GIPs 'size up' their progress, producing awareness of whether and how well subgoals are achieved, in turn stimulating adherence to the plan in motion or revisions to it. GIP's attend to whether they are understanding material being read, remembering what they have studied, and communicating clearly their intentions.

When GIPs detect performance shortcomings, they do not give up, but rather analyze the situation to determine how to alter strategies and plans to improve performance. For instance, if a GIP failed to understand a passage from Beowulf written in middle English, the miscomprehension would be detected. He or she might analyze the situation and determine strategic tactics to promote comprehension, including rereading slowly, rereading while consulting a middle English dictionary, going to the library and borrowing a modern English translation, or visiting the book shop to purchase published 'notes' about Beowulf. The GIP would then choose one (or more) of these options.

(3) GIPs have superior short-term memory capacity. Like all information processing models, the good strategy user model acknowledged short-term memory as an important 
determinant of thinking quality, largely because short-term capacity limits the amount of information held in consciousness at any one time. Those with greater short-term capacity can simultaneously process more than those with less capacity.

Individual differences in functional short-term capacity are determined only partially by neurological factors; strategic and knowledge-base differences also play a role. For instance, high capacity (i.e., as reflected by extensive recall on a short-term memory task such as digit span) sometimes reflects chunking of material into larger meaningful units, possible because of knowledge possessed by the learner (e.g., Dempster, 1978; Chi, 1978). Speed of information processing can also affect the amount in consciousness at any one time, although speed of processing also depends on prior knowledge. For instance, processing material in the native language can be accomplished more quickly than processing in a second language, at least when the second language is not yet mastered (e.g., Case, Kurland, \& Goldberg, 1982).

Regardless of the causes of short-term performance differences, efficient information processing is more likely for people possessing greater functional short-term capacity (see Case, 1985, for extensive theoretical development of this argument). For instance, some strategies can be performed effectively only by students who have high functional shortterm capacity compared to their peers (e.g., imaginal representation of prose, Pressley, Cariglia-Bull, Deane, \& Schneider, 1987; organizational strategies for list learning, Bjorklund \& Harnishfeger, 1987; Guttentag, 1984).

(4) GIPs use of strategies and other information processing components becomes automatized. Since recognizing when to execute strategies becomes automatic with practice, GIPs are efficient learners and problem solvers. Components once consciously sequenced and carried out are eventually executed from beginning to end with little expenditure of attention. Other aspects of information processing also become automatic with experience (e.g., retrieval and use of conceptual information stored in long-term memory; activation of appropriate motivational beliefs).

As automatic functioning increases, less conscious effort is required to carry out procedures. Hence, more short-term capacity is 'left over' to do other things simultaneously. For instance, because GIPs are intellectually active people, they generate many opportunities to practice tactics they have acquired. Thus, reading comprehension strategies become 'grooved' for the compulsive reader. As these strategies are executed ever more efficiently, GIPs can do other things to enhance their comprehension of materials being read (e.g., perhaps reflecting more on how contents relate to prior knowledge).

(5) GIPs possess extensive knowledge about important concepts, knowledge used appropriately. Mature thinkers have an enormous amount of information in long-term memory that can be used to mediate cognitive performance. For instance, their memory is largely determined by the degree they 'chunk' information into large meaningful units, with the ability to create such chunks directly tied to the extent and structure of prior knowledge networks. The classic example is the chess expert who remembers many morc pieces and positions in a mid-game array than the chess novice (e.g., Chi, 1978).

Prior knowledge sometimes eliminates the need to be strategic. Siegler (1988a, b) has studied children solving math problems by retrieving math facts from their knowledge base rather than relying on computational strategies. Strategies are used only if the child has not 
previously stored a relevant math fact in long-term memory or if the child is something of a perfectionist and wants to ensure the fact stored in long-term memory is correct. Anderson and his associates at Illinois (see Anderson \& Pearson, 1984) have demonstrated that people interpret and comprehend texts they are reading in light of prior knowledge, often to the point that their later recall of contents is distorted by prior knowledge (e.g., Brown, Smiley, Day, Townsend, \& Lawton, 1978). Finally, Schneider and his colleagues at the Max-Planck-Institute in München have demonstrated individual differences in general intelligence do not predict memory and comprehension of text as well as differences in prior knowledge about the domain covered in text (e.g., Schneider, Körkel, \& Weinert, 1989).

Not everyone uses their prior knowledge effectively. For example, university students report relatively few elaborations of text while learning (e.g., Christopoulos, Rohwer, \& Thomas, 1987; Schmeck, 1988). That intentional activation of prior knowledge increases learning dramatically (e.g., Pressley, Symons, McDaniel, Snyder, \& Turnure, 1988) suggests adults do not make the most of their prior knowledge. They often fail to activate stored information to mediate learning. In contrast, GIPs appropriately use their extensive prior knowledge.

(6) GIPs are appropriately confident. They are not afraid to tackle academic challenges. They are self-efficacious (Bandura, 1986), believing they can complete many tasks successfully, by matching their cognitive skills and conceptual knowledge to the new problem (Clifford, 1984). This is not arrogance, but reflects an awareness about the importance of their cognitive capacities. That is not to say good information processors never doubt their skills, knowledge levels, or beliefs. In fact, they do, with such doubt motivating efforts to revise or improve cognitive capacities. This mix of appropriate confidence and readiness to improve produces GIPs who apply themselves diligently to tasks at their level of competence, but who do not seek out or accept unreasonable assignments, at least not without assistance.

(7) GIPs believe self-improvement is possible and desirable. They see themselves as continually evolving, with their evolution under their own control. They envision 'possible selves' who possess different strategies, enriched metacognition, and more structured conceptual knowledge. GIPs aspire to become these possible selves and are willing to exert the effort to do so (Markus \& Nirius, 1986).

(8) GIPs live their lives so to encourage development of information processing capabilities. Human beings largely determine their own development (e.g., Bandura, 1986; Ford, 1987; Lerner \& Busch-Rossnagel, 1981; Scarr \& McCartney, 1983). One reason GIPs know multiple strategies and possess relevant conceptual information is they placed themselves in situations promoting acquisition of strategies and detailed conceptual knowledge. At an obvious level, they elect to stay in school and make the most of it. Less obviously, they might turn on the morning news on rising, read the paper over breakfast, listen to a variety of radio stations that span the entire range of musical taste, attend 'important' films, and read 'timely' and 'informative' books and magazines. They select friends who are intellectually engaging and engage those friends intellectually. When socializing, they talk about current events, debate ethical dilemmas that society faces, and try to understand the points of view held by their associates about important issues. There 
can be little doubt that the information processing skills and conceptual knowledge of GIPs continue to grow throughout their lives, largely through their self-directed efforts.

(9) GIPs are 'selected' into environments promoting processing competence. Important but limited resources, such as accelerated or enriched schooling, are allocited to those expected to benefit most from them. Once admitted into their choice of educational setting, additional selection occurs. For instance, students earning grades of $\mathrm{A}$ in honors chemistry are more likely to be sought out by faculty for special research projects than students earning Cs. More subtle selections occur as well. Bright people are likely to be sought out by other bright people for companionship. Thus, GIPs are afforded opportunities to enter relationships with other GIPs, who stimulate additional intellectual growth.

\section{Summary: Integrating the Components and Attributes of Good Information Processing}

The components of good information processing are summarized in Table 2.1. Intact neurology is the prerequisite for good information processing, allowing strategies, motivational beliefs, and conceptual knowledge to be stored in long-term memory. The conscious use of this array of knowledge (e.g., execution of strategies or retrieval of prior knowledge in order to comprehend text) takes place in consciousness (i.e., short-term memory), which is limited in capacity. This limitation is less for GIPs than for other people, largely because their extensive knowledge bases permit consolidation of information into larger chunks. Since the capacity constraint is on the number of chunks in memory (Miller, 1956), rather than their size, the GIP has greater functional short-term capacity, produced in large part by an extensive knowledge base.

GIPs not only have extensive knowledge about literature, science, current events, and the world in general they also know strategies appropriate for the tasks they face. Moreover, they know where and when to apply these strategies. The motivation to be strategic and to activate conceptual knowledge is high, given a strong belief that success is a product of appropriately-used strategies and existing knowledge. Thus, a GIP who must write a progress report about a project not only proceeds to do so, but does so confidently and efficiently. The GIP possesses the search, organizational, translation, and revision strategies comprising good writing plans (e.g., Flower, 1981). The GIP also has knowledge of the specific contents to include in the report, as well as how to retrieve or construct such information. More interestingly, the actual writing will improve the GIP's skills even further - for instance, more practice executing the writing and retrieval strategies promotes automaticity. Working through the information about the project probably increases both the volume and the organization of the GIP's knowledge base. Moreover, interactions with those who read the report may follow, enriching the knowledge base even more. In short, good information processing stimulates additional cognitive growth, affording opportunities to increase both knowledge and skill-based competence.

The styles and gencral tendencies of GIPs support the efficient integration of strategic and other conceptual knowledge to solve a range of complex tasks. GIPs are planful, aware of their cognitive actions (i.e., they consistently monitor behaviors), reflective, low in anxiety, and appropriately self-confident. These characteristics have permitted GIPs to do well in the past, and continue to foster cognitive development. GIPs are good thinkers, 
Table 2.1

Characteristics of Good Information Processors

\section{Intact Neurology}

The sensory systems are functioning well, permitting input into the central nervous system.

Relatively large short-term memory ${ }^{\mathrm{a}}$

Longmterm memory structures that permit storage of extensive conceptual, procedural, metacognitive, and motivational knowledge.

Information Stored in Long-Term Memory

Conceptual knowledge (e.g., important literary, scientific, historical, cultural, and world knowledge)

Procedural knowledge (strategies)

Metacognition about strategies (e.g., knowledge about where and when to apply each strategy that is known)

Supportive motivational beliefs (e.g., that achievement follows from use of strategies and conceptual knowledge well matched to a task)

General Cognitive Tendencies, Attitudes, and Styles

Planful

Monitor their performances

Self-efficacious

Selectively attend to task-relevant information

Shield themselves from distractions when working on a task

Reflective

Not overly anxious

Habitually relate currently processed information to prior knowledge

Provide themselves with many opportunities to practice information processing skills, so that many cognitive operations are practiced to the point of automatic functioning

Aspire to become (and believe they can become) better information processors

Elect themselves into situations that encourage growth of information processing characteristics

Are selected into situations that encourage growth of information processing characteristics

"Functional short-term memory is determined not only by neurological factors, but also by knowledge and strategy factors.

getting better. Since the general cognitive skills, tendencies, and information stored in long-term memory are fostered by formal education, the remainder of this article is concerned with how education can promote good information processing.

\section{The Development of Good Information Processing: The Role of Education}

Since instruction in good information processing requires a focus on all characteristics summarized in Table 2.1, it is necessarily a long-term endeavor. The unique emphasis here is the recognition that all components of good information processing are important and should be addressed directly by educational programs. (See Schneider \& Weinert, in press; for examples of many approaches emphasizing only one or a few of the elements in the model outlined here.)

\section{Emphasize Important Literary, Scientific, and Cultural Knowledge}

Although educators have advocated general education for a very long time, there is new urgency to these pleas in the United States, whose students have performed poorly on 
recent assessments of general knowledge (e.g., Ravitch \& Finn, 1987). When this fact is combined with renewed public awareness that knowledge of basic information is required to understand the world around us (e.g., Hirsch, 1987), a sense of crisis about education emerges. We believe such public perceptions and anxieties are appropriate, since extensive conceptual knowledge is essential to good information processing.

A solution to the problem is to identify information all students should know and ensure they are taught this essential content in school. This approach is exemplified by the recent publication of a 'dictionary' purported to contain information culturally literate Americans know (Hirsch, Kett, \& Trefil, 1988). The content was drawn from diverse sources including the Bible, proverbs, fine arts, politics, history and science. Although there is room for debate about exactly what information should be understood by all citizens (see Westbury \& Purves, 1988; for illuminating historical reviews of the controversies). Hirsch's (1987) position seems sensible given the large role of a welldeveloped knowledge base in determining competent thinking.

Educators should assure important material is taught at each level of the curriculum. Although Hirsch, Kett, and Trefil's (1988) dictionary is neither perfect nor complete, it provides a start. Persons who knew the information covered there would possess a respectable general knowledge base, one serving them well in many academic, business, and social situations. Nonetheless, teaching facts (or even understanding how important facts inter-relate) is not a sufficient goal for education. Knowing how to acquire those facts and use them productively is equally important, thus setting the stage for explicit and comprehensive strategy instruction within school curricula.

\section{Teach Strategies in Ways that Promote Good Information Processing}

A number of memory, reading comprehension, composition, and problem-solving strategies have been designed and validated in recent years (Pressley \& Associates, in press, provide detailed coverage). These strategies fit well into elementary curriculum, since they were designed to foster important goals of early education. With every passing year, there are more data suggesting strategy instruction can improve performance on important educational tasks such as reading and writing.

Educational researchers have also been active in identifying ways to teach strategies so that students not only learn the skills but also apply them appropriately in a self-regulated fashion. Successful strategy instruction has the following characteristics (for more extensive discussion, see Symons, Snyder, Cariglia-Bull, \& Pressley, 1989): (1) Strategies are taught a few at a time, intensively and extensively, as part of an ongoing curriculum. (2) New strategies are modelled and explained in detail by the teacher. Re-explanations are provided and tailored to difficulties actually encountered by students. (3) Explanations provided to students include information about when and where to use strategies. (4) Students are given practice applying the strategies to educational tasks. (5) Students are encouraged to monitor their performances, executing strategies matched to tasks until they are completed, shifting strategies when necessary to continue making progress toward a goal. (6) Students are told explicitly to generalize strategies. (7) Teachers heighten students' motivations to use strategies by making them aware strategies are at the heart of competent academic functioning. (8) Reflective, accurate processing rather than speedy 
processing (e.g., doing the task just to complete it on time) is emphasized. (9) Planning before acting is stressed, especially the identification of appropriate strategies. (10) High anxiety disrupts efficient strategy use, and thus teachers should reduce anxiety in their classrooms. (11) Methods are taught for ignoring distractions interfering with strategy execution.

\section{Motivate Acquisition and Use of Important Conceptual Information and Strategies}

Motivation is required to maximize students' acquisition of important academic content; it is also required if they are to use knowledge to the fullest possible extent. Although a number of important analyses about the role of motivation in education have appeared in the last decade, the most comprehensive discussions have been provided by Brophy and his colleagues (e.g., Brophy \& Kher, 1986). In brief, educators should try to exploit children's intrinsic motivations to learn: They should provide appropriately challenging tasks, neither too easy nor too difficult; provoke their students' curiosities; and make obvious the utility of school learning for children's lives (i.e., demonstrate the relevance of what is taught in school). One of the most important motivational roles for education is to teach that competence increases by using the skills and knowledge taught in school. When children apply school-learned knowledge and their performances are facilitated, there is opportunity to learn that success is due to their own integration and use of strategies and content information. Sometimes, however, the linkages between use of strategies, existing knowledge, and successful outcomes must be pointed out to children for them to come to this critical realization about self-efficacy (e.g., Borkowski, 1988; Försterling, 1985, 1988).

What is most appealing about Brophy's perspective is his recognition that the long course of education is filled with 'pitfalls', although students can be motivated to thrive during adversities encountered on this adventure. Students should be encouraged to view their efforts at improving cognitive resources as long-term investments rather than as short-term evaluations of personal competence - short-term difficulties are a natural part of learning and development.

\section{Encourage General Tendencies Supporting Good Information Processing}

Monitoring of performance, processing reflectively, planning for cognitive actions, diminishing anxiety, attending to tasks in the face of distractions, and seeking out academically stimulating activities (e.g., reading good books and magazines) should be encouraged during each school day. Consistent modelling and encouragement of these tendencies - through prompting to plan, modelling of reflective problem-solving combined with appropriate re-explanations when children encounter difficulties, and exposing students to teachers who enjoy academic activities and who themselves are intellectually stimulating - should do much to encourage children to internalize a cognitive style consistent with good information processing. Many of these themes have been echoed by Bandura (1986) and especially by McGillicuddy-De Lisi, De Lisi, Flaugher, and Sigel (1987). 


\section{The Challenge for Education}

There is no magic formula or quick fix to produce good information processing. The complexities of efficient, mature processing require years to develop. An emphasis on nonstrategic knowledge alone, strategies alone, metacognition alone, or motivation alone will not teach the next generation of children to read, write, and problem solve better than past generations.

A radical change is needed. Important contents and corresponding strategies should be taught beginning in preschool and continuing through graduate school. Educational environments can be restructured so students are motivated to learn what is taught and are encouraged to address academic challenges planfully, deliberately, calmly, and with a realistic sense of self-confidence.

Good information processing is indeed a rare commodity. It might become commonplace if educators took seriously the challenge to teach essential knowledge, strategies, metacognition, motivation, and general cognitive tendencies to every student.

\section{References}

Anderson, R. C., \& Pearson, P. D. (1984). A scheme-theoretic view of basic processes in reading. In P. D. Pearson (Ed.), Handbook of reading research (pp. 255-291). New York, NY: Longman.

Bandura, A. (1986). Social foundations of thought and action: A social cognitive theory. Englewood Clifs, NJ: Prentice Hall,

Bjorklund, D.F., \& Harnishfeger, K. K. (1987). Developmental differences in the mental effort requirements for use of an organizational strategy in free recall. Journal of Experimental Child Psychology, 44, $109-125$.

Borkowski, J. G. (1988). Understanding inefficient learning: Attributional beliefs and the training of memory and comprehension strategies. In M. Gruneberg. P. Morris, \& R. Sykes (Eds.), Practical aspects of memory (Vol. 2, pp. 287-293). Chichester \& New York: Wiley.

Borkowski, J. G., Carr, M., Rellinger, E. A., \& Pressley, M. (in press). Self-regulated strategy use: Interdependence of metacognition, attributions, and self-esteem. In B. F. Jones (Ed.), Dimensions of thinking: Review of research. Hillsdale, NJ: Erlbaum \& Associates.

Brophy, J., \& Kher, N. (1986). Teacher socialization as a mechanism for developing student motivation to learn. In R. Feldman (Ed.), The social psychology of education (pp. 257 288). Cambridge, England: Cambridge University Press.

Brown, A. L., Smiley, S. S., Day, J. D., Townsend, M. A. R., \& Lawton, S. C. (1977). Intrusion of a thematic idea in children's comprehension and retention of stories. Child Development, 48, $1454-1466$.

Case, R. (1985). Intellectuat development. Urlando, HL: Academic Press.

Case, R., Kurland, D. M., \& Goldberg, J. (1982). Operational efficiency and the growth of short-term memory span. Journal of Experimental Child Psychology, 33, 386-404.

Chi, M. T. H. (1978). Knowledge structure and memory development. In R. S. Siegler (Ed.). Children's thinking: What develops? (pp. 73-96). Hillsdale, NJ: Erlbaum \& Associates.

Christopoulos, J. P., Rohwer, W. D., Ir., \& Thomas, J. W. (1987). Grade level differences in students' study activities as a function of course characteristics. Contemporary Educational Psychology, 12, 303-323.

Clifford, M. M. (1984). Thoughts on a theory of constructive failure. Educational Psychologist, 19, $108-120$.

De Lisi, R. (1987). A cognitive-developmental model of planning. In S. L. Friedman, E. F. Scholnick, \& R. R. Cocking (Eds.), Blueprints for thinking: The role of planning in cognitive development (pp. 79-109). Cambridge: Cambridge University Press.

Dempster, F. N. (1978). Memory span and short-term memory capacity: A developmental study. Journal of Experimental Child Psychology, 26, 419-431.

Flower, L. (1981). Problem-solving strategies for writing. New York, NY: Harcourt, Brace, Jovanovich.

Försterling, F. (1985). Attributional retaining: A review. Psychological Bulletin, 98, 495-512.

Försterling, F. (1988). Attribution theory in clinical psychology. Chichester \& New York: Wiley.

Ford, D. H. (1987). Humans as self-constructing living systems: A developmental perspective on behavior and personality. Hillsdale, NJ: Erlbaum \& Associates.

Guttentag, R. E. (1984). The mental effort requirement of cumulative rehearsal: A developmental study. Journal of Experimental Child Psychology, 37, 92-106.

Hirsch, E. D., Jr. (1987). What every American needs to know. New York: Houghton Mifflin. 
Hirsch, E. D., Jr., Kett, J. F., \& Trefil, J. (1988). The dictionary of cultural literacy. Boston: Houghton Mifflin.

Hoc, J.-M. (1988). Cognitive psychology of planning. London: Academic Press.

Lerner, R. M., \& Busch-Rossnagel, N. (Eds.) (1981). Individuals as producers of their own development. New York: Academic Press.

Markus, H., \& Nurius, P. (1986). Possible selves. American Psychologist, 41, 954-969.

McGillicuddy-De Lisi, A. V., De Lisi, R., Flaugher, J., \& Sigel, I. E. (1987). Fantilial influences on planning. In S. L. Friedman, E. F. Scholnick, \& R. R. Cocking (Eds.), Blueprints for thinking: The role of planning in cognitive development (pp. 395-427). Cambridge: Cambridge University Press.

Miller, G. A. (1956). The magical number seven, plus or minus two: Some limits on our capacity for processing information: Psychological Review, 63, 81-97.

Miller, G., Galanter, E., \& Pribram, K. (1960). Plans and the structure of behavior. New York, NY; Holt, Rinehart, \& Winston.

Pressley, M. (1986). The relevance of the good strategy user model to the teaching of mathematics. Educational Psychologist, 21, 139-161.

Pressley, M., \& Associates (in press). Cognitive strategy instruction that really improves children's academic performances. Cambridge, MA: Brookline Books.

Pressley, M., Borkowski, J. G., \& Schneider, W. (1987). Cognitive strategies: Good strategy users coordinate metacognition and knowledge. In R. Vasta \& G. Whitehurst (Eds.), Annals of child development (Vol. 5, pp. 89-129). New York. NY: JAI Press.

Pressley, M., Cariglia-Bull, T., Deane, S., \& Schneider, W. (1987). Short-term memory, verbal competence, and age as predictors of imagery instructional effectiveness. Journal of Experimental Child Psychology, 43, $194-211$.

Pressley, M., Symons, B. L., McDaniel, M. A., Snyder, B. L., \& Turnure, J. E. (1988). Elaborative interrogation facilitates acquisition of confusing facts. Journal of Educational Psychology, 80, $268-278$.

Ravitch, D., \& Finn, C. E., Jr. (1987). What do our 17-year-olds know? A report of the first national assessment of history and literature. New York: Harper \& Row.

Scarr, S., \& McCartney, K. (1983). How people make their own environments: A theory of genotypel environment interactions. Child Development, 54, $424-435$.

Schmeck, R. R. (1988). Individual differences and learning strategies. In C. Weinstein, P. Alexander, \& E. Goetz (Eds.), Learning and study strategies: Issues in assessment, instruction, and evaluation (pp. 171-191). Orlando, FL: Academic Press.

Schneider, W., \& Weinert, F. E. (Eds.) (1989). Interactions among aptitudes, strategies, and knowledge in cognitive performance. New York \& Berlin: Springer-Verlag.

Schneider, W., Körkel, J., Weinert, F. E. (1989). Domain-specific knowledge and memory performance: Comparison of high and low aptitude children. Journal of Educational Psychology, 81, 306-312.

Siegler, R. S. (1988a). Individual differences in strategy choices: Good students, not-so-good students, and perfectionists. Child Development, 59, 833-851.

Siegler, R. S. (1988b). The perils of averaging data over strategies: An example from children's addition. Journal of Experimental Psychology: General, 116, 250-264.

Symons, S., Snyder, B. L., Cariglia-Bull, T., \& Pressley, M. (1989). Why be optimistic about cognitive strategy instruction? In C. B. McCormick, G. E. Miller, \& M. Pressley (Eds.), Cognitive strategy research: From basic research to education applications (pp. 3-32). New York \& Berlin: Springer-Verlag.

Westbury, I., \& Purves, A. C. (Eds.) (1988). Cultural literacy and the idea of general education: Eighty-seventh yearbook of the National Society for the Study of Education. Chicago: National Society for the Student of Education. 